$05.1 ; 06.5$

\title{
Исследование методом наноиндентирования твердости и модуля Юнга в тонких приповерхностных слоях карбида кремния со стороны Si- и C-граней
}

\author{
(C) А.В. Осипов ${ }^{1}$, А.С. Гращенко ${ }^{1}$, А.Н. Горляк ${ }^{2}$, А.О. Лебедев ${ }^{2,3}$, В.В. Лучинин ${ }^{2}$, А.В. Марков ${ }^{2}$, \\ М.Ф. Панов ${ }^{2}$, C.A. Кукушкин ${ }^{4}$ \\ ${ }^{1}$ Институт проблем машиноведения РАН, Санкт-Петербург, Россия \\ ${ }^{2}$ Санкт-Петербургский государственный электротехнический университет „ЛЭТИ“, Санкт-Петербург, Россия \\ ${ }^{3}$ Физико-технический институт им. А.Ф. Иофффе РАН, Санкт-Петербург, Россия \\ ${ }^{4}$ Университет ИТМО, Санкт-Петербург, Россия \\ E-mail: andrey.v.osipov@gmail.com
}

Поступило в Редакцию 20 апреля 2020г.

В окончательной редакции 29 апреля 2020г.

Принято к публикации 29 апреля 2020 г.

\begin{abstract}
Представлены результаты исследования методом наноиндентирования твердости и модуля Юнга приповерхностных слоев гексагонального карбида кремния $4 \mathrm{H}$-SiC, полученного модифицированным методом

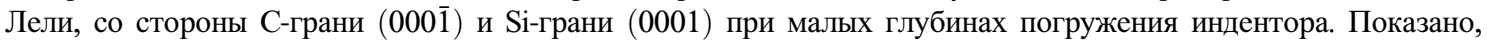
что различия в упругих свойствах и твердости $\mathrm{SiC}$ распространяются от поверхности в глубь кристалла примерно на глубину $60 \mathrm{~nm}$. Значение модуля Юнга у С-грани практически совпадает с модулем Юнга

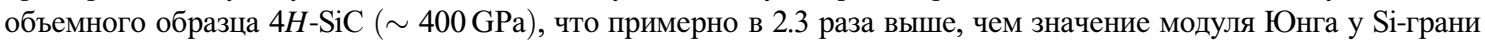
на глубине от 0 до $35 \mathrm{~nm}(\sim 170 \mathrm{GPa})$. Значение коэффициента твердости $\mathrm{SiC}$ в среднем примерно в 1.5 раза выше у поверхности С-грани (000) $)$, чем у Si-грани (0001), на глубине от 0 до $60 \mathrm{~nm}$. Поскольку при деформации или разрушении кристалла (формировании трещин) образуется новая поверхность, на основании полученных данных сделан вывод, что энергия поверхности С-грани также примерно в 1.5 раза выше, чем энергия поверхности $\mathrm{Si}-г$ рани.
\end{abstract}

Ключевые слова: наноиндентирование, карбид кремния, твердость, межфазная энергия.

DOI: 10.21883/PJTF.2020.15.49747.18346

Карбид кремния $(\mathrm{SiC})$ - широкозонный полупроводник, обладающий рядом уникальных физикомеханических свойств, таких как высокая термическая, радиационная и химическая стойкость, высокая твердость и др. Эти свойства делают $\mathrm{SiC}$ перспективным материалом для создания сильноточных и высокочастотных электронных приборов [1]. Кроме того, $\mathrm{SiC}$ вызывает в настоящее время значительный интерес в связи с использованием его в качестве подложек для роста других широкозонных полупроводников, а также в связи с получением эпитаксиального графена посредством высокотемпературной сублимации кремния с поверхности $\mathrm{SiC}$ [2]. Ряд свойств $\mathrm{SiC}$ зависит от того, какая грань используется: Si-грань (0001) или С-грань (0001) (рис. 1). Например, в работе [3] показано, что с повышением температуры возникает различие в твердости кристаллов $\mathrm{SiC}$ в зависимости от того, какая грань (C- или Siгрань) используется. Если при комнатной температуре для микрометровых глубин погружения индентора разницы практически нет, то при повышении температуры (до $1200^{\circ} \mathrm{C}$ ) С-грань становится тверже примерно на 15\%, чем Si-грань. В работе [3] это объясняется различием в природе ядер дислокаций, которые образуются при высоких температурах в процессе индентирования Si- и C-граней в микрометровом масштабе. Однако помимо указанных различий при микрометровом масштабе ин- дентирования должны наблюдаться различия и в нанометровом масштабе индентирования, потому что энер-

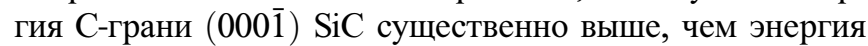
Si-грани (0001) [4]. Хорошо известно, что многие механические свойства, например твердость кристалла, различные упругие характеристики, тесно связаны с энергией его поверхности, так как в процессах деформации и разрушения образуется новая поверхность [5]. Поэтому очевидно, что в некоторой приповерхностной области механические свойства кристалла $\mathrm{SiC}$ будут зависеть от типа поверхности [5]. Однако до сих пор зависимость механических свойств $\mathrm{SiC}$ от типа грани практически не исследовалась, что было вызвано нанометровым масштабом этой зависимости. С развитием наноинденторов и компьютерной техники изучение таких зависимостей становится возможным. Настоящая работа посвящена изучению методом наноиндентирования упругих свойств

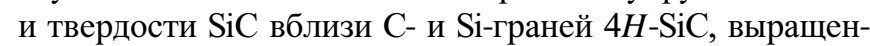
ного модифицированным методом Лели.

Модифицированным методом Лели на затравках-плас-

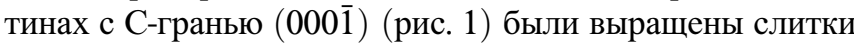
$4 H$-политипа с экспериментально подобранными температурными и скоростными режимами, обеспечивавшими практически одновременный рост и стабилизацию в базисной плоскости $4 H$-политипа [6]. Температурные градиенты в процессе роста составляли $10-20 \mathrm{~K} / \mathrm{cm}$; под- 


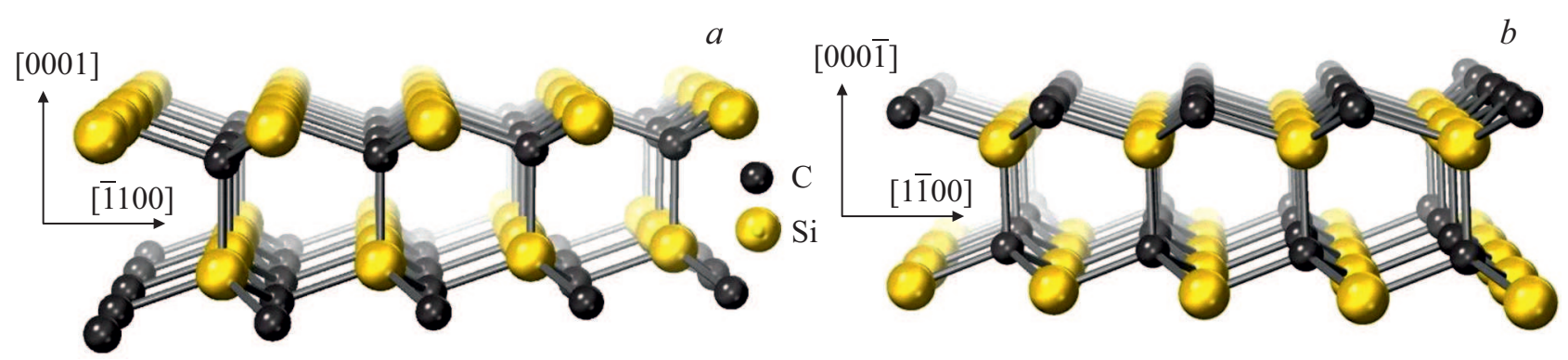

Рис. 1. Si-грань (0001) (a) и C-грань $(000 \overline{1})(b)$ гексагонального карбида кремния без учета реальной реконструкции поверхности.

держивался уровень легирования азотом $\sim 5 \cdot 10^{18} \mathrm{~cm}^{-3}$. На этапе получения монокристаллических пластин $\mathrm{SiC}$ после обдирки выращенного слитка с целью обозначения кристаллографического направления [11̄ㅣ, а также исключения неоднозначности распознавания Si- и С-граней на скругленный слиток посредством шлифовки наносились большой и малый базовые срезы. Точные положения срезов определялись рентгеновским методом. Последующие стадии получения и обработки пластин из слитка реализовались уже с детерминированием по кристаллографическим направлениям. Дополнительное определение типа грани обработанных пластин $\mathrm{SiC}$ возможно различными методами, в частности методом химического травления, например, в расплаве КОН. На этапе производства в целях контрольной проверки достаточно подвергнуть указанной процедуре любую полированную пластину, вырезанную из размеченного слитка. На Si-грани декорируются структурные дефекты, наблюдается селективное травление, в то время как на противоположной грани (С-грани) наблюдается изотропное травление [6]. Различие в рельефе травленой пластины можно легко наблюдать невооруженным глазом или в оптический микроскоп. Окончательная подготовка экспериментальных образцов включала двухстадийную четырехчасовую механическую полировку каждой поверхности двумя различными алмазными пастами с размером зерна $\leqslant 3$ и $\leqslant 1 \mu \mathrm{m}$ с применением тканевого притира из искусственного волокна. Измерение суммарной толщины слоя шероховатости и слоя естественного оксида на эллипсометре M-2000D J.A. Woollam с вращающимся компенсатором в диапазоне энергий $0.7-6.5 \mathrm{eV}$ дает следующие значения: общая эффективная шероховатость

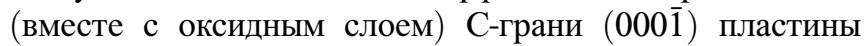
$\mathrm{SiC}$ равна $l_{\mathrm{C}}=8 \mathrm{~nm}$, шероховатость Si-грани (0001) пластины $\mathrm{SiC}$ равна $l_{\mathrm{Si}}=5 \mathrm{~nm}$.

Полированные пластины 4H-SiC подвергались нагрузке на наноинденторе Nanotest 600 фирмы Micromaterials как С-гранью (0001), так и Si-гранью (0001) (рис. 1). При этом использовался алмазный индентор Берковича [7] с радиусом закругления $100 \mathrm{~nm}$. Скорость нагрузки была постоянной и равной $0.5 \mathrm{mN} / \mathrm{s}$, а максимальная сила нагрузки на индентор не превышала $1.5 \mathrm{mN}$. Среднее время между измерениями примерно равно $0.05 \mathrm{~s}$. Для того чтобы учесть различие в шероховатостях у С-грани и $\mathrm{Si-грани,} \mathrm{в} \mathrm{качестве} \mathrm{начала} \mathrm{отчета} \mathrm{глубины} \mathrm{погружения}$ индентора выбиралась усредненная точка пересечения кривой нагрузки и оси абсцисс, т.е. начало слоя $\mathrm{SiC}$. Прежде всего необходимо отметить, что кривая разгрузки практически полностью совпадала с кривой нагрузки, т.е. при глубинах погружения наноиндентора $\sim 60 \mathrm{~nm}$ и менее кристалл карбида кремния является упругим материалом. Разница между процессами нагружения $\mathrm{C}$-грани и $\mathrm{Si}$-грани представлена на рис. 2. При одинаковой нагрузке в интервале $0.3-1.3 \mathrm{mN}$ индентор глубже погружается в Si-грань примерно на 8-10 nm. При глубине погружения менее $h<35 \mathrm{~nm}$ зависимости нагрузки $F$ от глубины погружения можно аппроксимировать степенной функцией $F \sim h^{3 / 2}$. Очевидно, это связано с тем, что при таких малых глубинах погружения индентор Берковича идентичен сферическому индентору, для которого в случае упругого взаимодействия с образцом справедливо соотношение Герца [7]:

$$
F=\frac{4}{3}\left[\frac{1-v_{s}^{2}}{E_{s}}+\frac{1-v_{i}^{2}}{E_{i}}\right]^{-1} h^{3 / 2} \sqrt{R},
$$

где $E$ - модуль Юнга, v - коэффициент Пуассона, индексы $s$ и $i$ относятся к образцу и индентору соответственно, $R$ - радиус наконечника сферического индентора. Сопоставляя экспериментальные данные при $h<35 \mathrm{~nm}$ (рис. 2) с соотношением (1), можно найти модуль Юнга для С- и Si-граней: $E_{\mathrm{C}}=400 \mathrm{GPa}$, $E_{\mathrm{Si}}=170 \mathrm{GPa}$. Проведение аналогичных измерений для тестового образца кварца позволяет оценить погрешность данных измерений модуля Юнга как 5\%. Следует отметить, что модуль Юнга для С-грани практически совпадает с модулем Юнга объемного образца $4 H-\mathrm{SiC}$ $E=400 \mathrm{GPa}$, который измеряется в пластической области при глубинах погружения $\sim 1000 \mathrm{~nm}$. Иными словами, при малых глубинах погружения $\mathrm{Si}$-грань в 2.3 раза менее упругая, чем С-грань или объемный кристалл.

Расчет твердости кристалла $\mathrm{SiC}$ при различных глубинах погружения индентора, выполненный на основе реальной геометрии индентора, показан для обеих граней на рис. 3. Твердость $H$ однородного кристалла всегда нарастает при увеличении глубины погружения индентора, но в случае $4 H$-SiC она нарастает по-разному для C- и Si-граней. Твердость у С-грани нарастает до твердости объемного кристалла $H_{\mathrm{SiC}} \approx 35 \mathrm{GPa}$ значительно быстрее, чем у Si-грани. В среднем при глубинах 


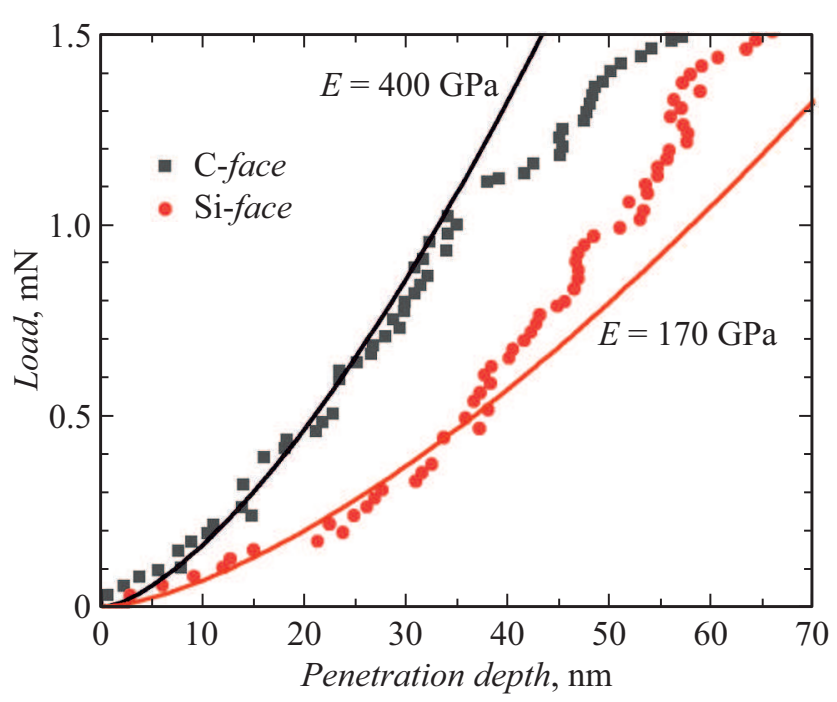

Pис. 2. Диаграмма нагрузка $F$-глубина погружения $h$ для С-грани $(000 \overline{1})$ и $\mathrm{Si}$-грани (0001) $4 H-\mathrm{SiC}$ в упругой области погружения $<60 \mathrm{~nm}$ при использовании индентора Берковича с радиусом закругления $100 \mathrm{~nm}$. Сплошными линиями показаны теоретические зависимости (1), полученные для значений модуля Юнга образца 400 и $170 \mathrm{GPa}$.

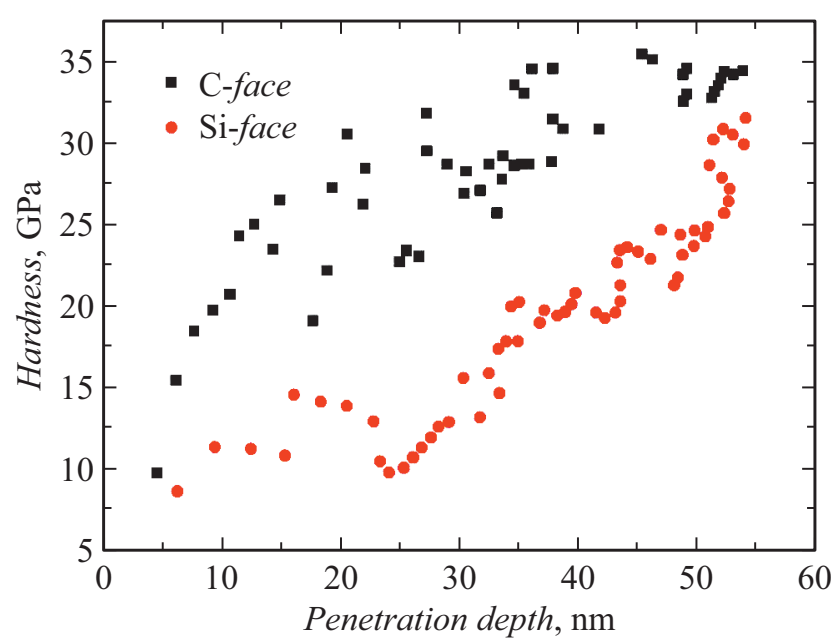

Рис. 3. Зависимость твердости кристалла $4 H-\mathrm{SiC}$ для С-грани $(000 \overline{1})$ и $\mathrm{Si}-г$ рани $(0001)$ в зависимости от глубины погружения индентора.

погружения от 10 до $50 \mathrm{~nm}$ твердость С-грани примерно в 1.5 раза выше, чем у Si-грани. Данный результат напрямую связан с тем, что энергия поверхности Cграни выше, чем энергия поверхности Si-грани, поэтому процесс образования новой поверхности у С-грани протекает тяжелее.

Таким образом, в работе напрямую показано различие упругих свойств и твердости $4 H-\mathrm{SiC}$ в приповерхностных слоях C- и Si-граней. Данное различие особенно заметно при глубинах погружения индентора менее $60 \mathrm{~nm}$. При одинаковых нагрузках, меньших $1.2 \mathrm{mN}$, глубина погружения индентора в С-грань на $8-10 \mathrm{~nm}$

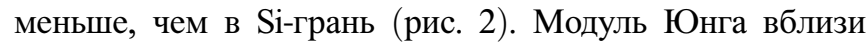
С-грани практически совпадает с модулем Юнга объемного кристалла $E=400 \mathrm{GPa}$ в направлении (0001), тогда как модуль Юнга вблизи Si-грани на глубине до $35 \mathrm{~nm}$ в 2.3 раза меньше $(170 \mathrm{GPa})$. Твердость кристалла $4 H-\mathrm{SiC}$ нарастает с глубиной погружения быстрее у С-грани, при глубинах погружения от 10 до $50 \mathrm{~nm}$ твердость $\mathrm{SiC}$ у С-грани в среднем примерно в 1.5 раза выше, чем у Si-грани (рис. 3). Поскольку твердость кристалла напрямую связана с энергией его поверхности [4], на основании полученных данных можно сделать вывод, что энергия поверхности С-грани кристалла $\mathrm{SiC}$ примерно в 1.5 раза выше энергии поверхности $\mathrm{Si}$-грани, что согласуется с данными моделирования методом функционала плотности $[5,8,9]$. Влияние этой разницы распространяется в глубь кристалла примерно на $60 \mathrm{~nm}$.

\section{Благодарности}

Исследования проводились с использованием оборудования уникальной научной установки „Физика, химия и механика кристаллов и тонких пленок“" ФГУП ИПМаш РАН (Санкт-Петербург).

\section{Финансирование работы}

А.В. Осипов и А.С. Гращенко выполняли свою часть работы в рамках госзадания ФГУП ИПМаш РАН № AААА-A18-118012790011-3. С.А. Кукушкин осуществлял свою часть работы в рамках проекта Российского научного фонда № 19-72-30004.

\section{Конфликт интересов}

Авторы заявляют, что у них нет конфликта интересов.

\section{Список литературы}

[1] Fan J., Chu P.K. Silicon carbide nanostructures. Fabrication, structure, and properties. Cham: Springer, 2014. $330 \mathrm{p}$.

[2] Лебедев А.А., Котоусова И.С., Лаврентьев А.А., Лебедев С.П., Макаренко И.В., Петров В.Н., Титков А.Н. // ФTT. 2009. T. 51. B. 4. C. 783-786.

[3] Ning X.-J., Huvey N., Pirouz P. // J. Am. Ceram. Soc. 1997. V. 80. P. 1645-1652. DOI: 10.1111/j.1151-2916.1997.tb03033.x

[4] Filimonov S.N. // Mater. Sci. Forum. 2015. V. 821-823. P. 363366. DOI: 10.4028/www.scientific.net/MSF.821-823.363

[5] Ребиндер П.А., Щукин Е.Д. // УФН. 1972. Т. 108. № 1. С. $3-$ 42.

[6] Авров Д.Д., Лебедев А.О., Таиров Ю.М. // ФТП. 2016. Т. 50. B. 4. C. $501-508$.

[7] Fischer-Cripps A.C. Nanoindentation. Heidelberg: Springer, 2011. $277 \mathrm{p}$.

[8] Osipov A.V. // J. Phys. D: Appl. Phys. 1995. V. 28. P. 1670 1679. DOI: $10.1088 / 0022-3727 / 28 / 8 / 016$

[9] Kaneko T., Yamasaki T., Tajima N., Ohno T. // Surf. Sci. 2016. V. 647. P. 45-50. DOI: 10.1016/j.susc.2015.11.019 